\title{
Geomatics for Terrain's Deformation Monitoring: The H2020 LiquefACT Field Trial in Pieve di Cento, Italy
}

\author{
Vittorio Casella (D) and Marica Franzini ${ }^{(\otimes)}(\mathbb{D}$ \\ Department of Civil Engineering and Architecture, University of Pavia, Pavia, Italy \\ \{vittorio.casella, marica.franzini\}@unipv.it
}

\begin{abstract}
The paper presents a case study on the application of Geomatics to terrain's deformation monitoring. Within the EU H2020 LiquefACT project, the Laboratory of Geomatics of the University of Pavia (Italy) was appointed to quantify the subsidence suffered by the terrain due to some trials conducted in the test site of Pieve di Cento, Northern Italy. Geomatics has long been used for deformation monitoring, but present paper deals with two peculiar elements: the constraints given by the test field, its layout, the allowed and forbidden actions, that forced the surveyors to elaborate an unconventional surveying design, and the use of a stateof-the-art instrument, the Trimble SX10. It mainly is a high-level topographic total station; being robotized, it has interesting laser scanning capabilities. In the paper, the survey design will be illustrated and discussed, and a selection of the obtained results will be presented. They highlight how much geomatics can be flexible and adaptable and, at the same time, precise and accurate.
\end{abstract}

Keywords: Geomatics · Topographic survey · Laser scanner · Deformation monitoring $\cdot$ Accuracy $\cdot$ Precision

\section{Introduction}

Geomatics can be defined as a systemic, multidisciplinary, integrated approach to select the instruments and the appropriate techniques for collecting, storing, integrating, modelling, analysing, retrieving at will, transforming, displaying and distributing spatially georeferenced data from different sources with well-defined accuracy characteristics, continuity and in a digital format [1]. Geomatics includes several disciplines such as geodesy, surveying, global navigation satellite systems, photogrammetry, lidar, cartography, GIS, theory of errors. Most often, they are used in an integrated way, as it happened in the described experiment. One distinguishing feature of geomatics is the capability of performing high precision measurements in a controlled way. This means that not only unknowns, such as distances and coordinates, are measured, but their statistical uncertainty is also assessed. 
Thanks to this versatility, geomatics has always had several areas of application such as cultural heritage [2,3], urban and regional planning [4-6] and natural hazard management $[7,8]$ and forensic sciences $[9,10]$ and monitoring. Geomatics supports monitoring with a variety of instruments and techniques but, in this introduction, only a quick overview will be given on those used inside this contribution which means total station and terrestrial laser scanner.

Total Station (TS) is the more traditional instruments and has numerous advantages [11] that include the high accuracy, the capability to perform indoor and in urban canyon measurements [12] and, with new generations of instruments completely robotized, the automation of targets recognition and observation [13, 14]. Among disadvantages, there could be limitation due to adverse weather conditions [15] and the necessity to have a clear line of sight between TS and the prisms. There are several applications fields; here are some examples: [16] shows the use of TS for bridge vibrations monitoring in a lab simulation and in a field experiment in Graz (Austria); [17] has used four TS to estimate the displacements suffered by a metro tunnel in Lisbon (Portugal) cause by a mud flooding; [18] reports an experience on the use of TS for the monitoring of an earthfill dam in southern California obtaining good results when atmospheric refraction correction has been taken into consideration.

Terrestrial Laser Scanner (TLS) is widely used in monitoring and there is abundance of articles on its use in literature. TLS has advantages and disadvantages too [19]: thank to the high density of the collected points, it allows to perform a continuous 3D analysis in a quick and completely autonomous way; however, it is more expensive, requires clear line of sight, as for TS, and is less reliable in time series when a stable setting up is not guarantee [20,21]. It was used for several application such as landslide displacements studies [21-23], glaciers [24], bridges [25-27] and dams [28, 29]. The reported experiences agree in arguing that TLS monitoring gives important contribution to the deformation analysis thanks to high density data [20]; moreover, the obtained accuracies satisfy the quality requirements [30] even if the survey geometry must be carefully planned [31].

As with almost every research area, the field of surveying and its equipment evolve with the technological innovations leading to ever faster, more accurate and more versatile devices. The recent Trimble SX10 scanning total station [32] belongs to this category of multi-sensor systems. The system is, at the same time, a topographical total station, capable to carry out high quality topographic measurements, and a terrestrial laser scanner; besides, it has three calibrated cameras able to acquire oriented images, if necessary. In literature, a few experiences are available on its use such as [33] that has tested the instrument in several contexts comparing results with those obtained from traditional systems; the paper also reports a technical properties review.

\section{Introduction to the Experiment of Pieve di Cento}

The EU H2020 LiquefACT project sets out to achieve a comprehensive understanding of Earthquake Induced Liquefaction Disasters (EILDs), the applications of the mitigation techniques, and the development of more appropriate techniques tailored to each specific scenario, for both European and worldwide situations (http://www.liquefact.eu/). A test 
trial was organized in Pieve di Cento (BO), Northern Italy (Fig. 1b), to test some mitigation methods. Tests lasted two days, $22^{\text {nd }}$ and $23^{\text {rd }}$ October 2018 . In that occasion, the Laboratory of Geomatics of the University of Pavia was appointed to perform geomatic surveying and to quantify subsidence induced by the experiment (Fig. 1).

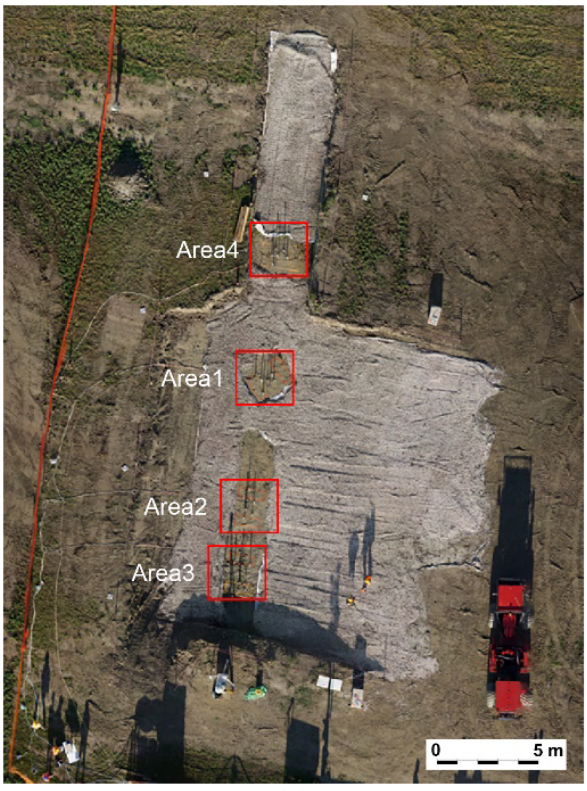

(a)

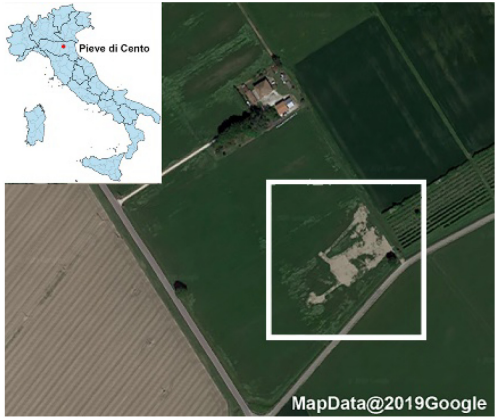

(b)

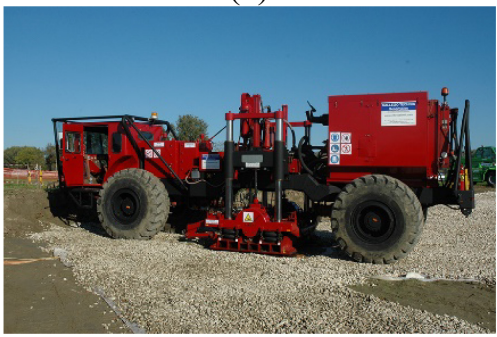

(c)

Fig. 1. An overview of the Pieve di Cento test field and the Megashaker vehicle: (a) The four test areas outline on the background of the orthophoto generated by UAV-acquired data; (b) The excerpt from the Google Satellite Data (MapData@2019Google); (c) The Megashaker vehicle used to simulate earthquakes.

The test field was a large dig where four test areas were prepared, which were characterized by different mitigation methods for soil liquefaction. Figure 2a shows a site overview together with the test area outlines: Area1 had virgin soil because no mitigation techniques were applied, Area2 and Area3 were treated with horizontal drains having different section shape, while the Induced Partial Saturation (IPS) method was applied to Area4. In each area, several simulated earthquake shocks were applied by a special vehicle which is capable to simulate an earthquake (Fig. 2c). The shaking actions are produced by a hydraulic system acting on two plates, once for each side of the vehicle, which are laid on the ground and transmit vibrations to the terrain, at a defined frequency; noticeably, the machine can produce P- and S-waves. The described vehicle is called megashaker in the documents of the LiquefACT project and we will adopt that name since now. The typical sequence of the experiment was: the megashaker was moved to one of the four areas and plates were laid on the terrain. Some time was waited so that terrain strains were dissipated. A first shake was performed having planned duration and frequency and activities were stopped for an appropriate time; then, another shake 
was applied with same or different parameters. After a certain number of shakes in the same area, the vehicle was moved to another one according to the initial plan and to the on-the-fly decisions taken by the management team. The Laboratory of Geomatics was appointed to perform geomatic surveying and to quantify subsidence induced by these experiments.

\section{The Geomatic Surveying Performed in Pieve di Cento}

To effectively design a topographic survey, it is necessary to know the goals, in terms of resolution and precision. The scientists who organized the experiment did not have a sharp idea of the expected size of induced subsidence; they considered desirable the capability of detecting movements of a few millimetres and wanted to be sure to detect those of $1 \mathrm{~cm}$ and up. Therefore, a high-quality survey was planned, which had nevertheless to cope with the many constraints posed by the field test, as it will be explained in the following. Two techniques were taken into consideration: topographic surveying and terrestrial laser scanning.

Topographic surveying is based on the use of topographic total station instruments, which measure horizonal and vertical angles and slope distance. Typically, measurements are taken from a stable point of known coordinates; specific target points are observed, and their coordinates are calculated. Topographic surveying is very precise, and coordinates can be determined with an uncertainty of $0.5 \mathrm{~mm}$, if site has limited size and particular care is taken.

Terrestrial laser scanning is performed by instruments measuring the same quantities as total stations. Difference is that they automatically and quickly scan the selected scene thus producing a dense point cloud. Point clouds are very attractive as they seem a sort of a continuous model, including all the details of reality. An often-underestimated issue is that point density is highly variable as decreases as the distance from the instrument increases. Anyway, the major disadvantage of such technique is, for the considered scenario, that a single scan can take from several minutes to hours. Dedicated laser scanning can be performed with dedicated instruments, which are capable to acquire between $10^{5}$ and $10^{6}$ points per second.

In the Pieve di Cento site, Trimble SX10 scanning total station was used instead, for both types of surveying. It is a state-of-the-art multi-sensor systems since the it is, at the same time, a topographical total station, capable to carry out high quality topographic measurements, and a terrestrial laser scanner.

\subsection{Topographic Survey}

The integrated Trimble SX10 instrument was adopted which is, first, a topographic total station of the highest quality, being able to measure angles with a precision of 1 arcsec and distances with a precision of $1 \mathrm{~mm}$ plus $1.5 \mathrm{ppm}$ [32]. Before discussing the survey schema, it is worth mentioning that the general design of the Pieve di Cento experiment was performed long time before and dealt with several aspects such as the paths followed by the megashaker and the position of all other geotechnics instruments. 
Geomatics monitoring was not planned and therefore, when it was designed, it was mandatory to cope with the constraints coming from other features of the site.

It was not easy to monitor terrain's subsidence in the described framework, because the part of the terrain that suffered the major sinking was hidden by the vehicle; moreover, it was not easy to ascertain whether superficial shape modifications simply pointed out shifting of the gravel or an actual deformation. We concluded that, targeting the shown plate, was the most reliable way to monitor the terrain underneath.

The shaking actions were produced by the vehicle thanks to hydraulic mechanisms and transmitted to the terrain through the plates lying on it. Plates can be considered integral to the terrain itself because of its significant weight and because wheels were unloaded from the megashaker weight, during the shake; therefore, each displacement measured on the plates can be reasonably connected to a subsidence suffered by the terrain. To quantify these displacements, several topographic targets were placed on the plate, on the side visible from the instrument. Figure 2a shows the targets fixed on a plate of the vehicle; each marker, Fig. $2 b$, was identified with a letter that also indicates the measuring order. Section 4 will illustrate the results obtained from targets' measurements.

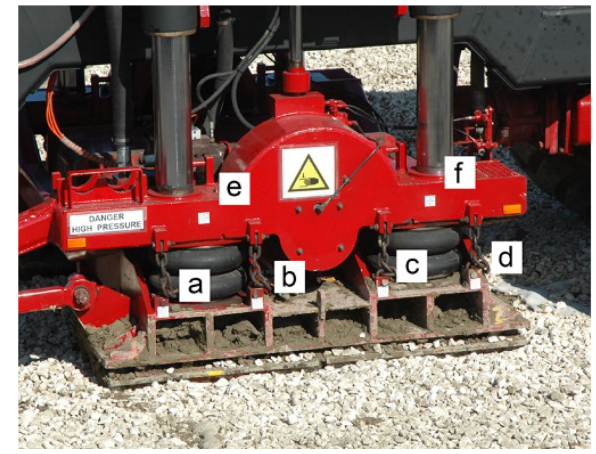

(a)

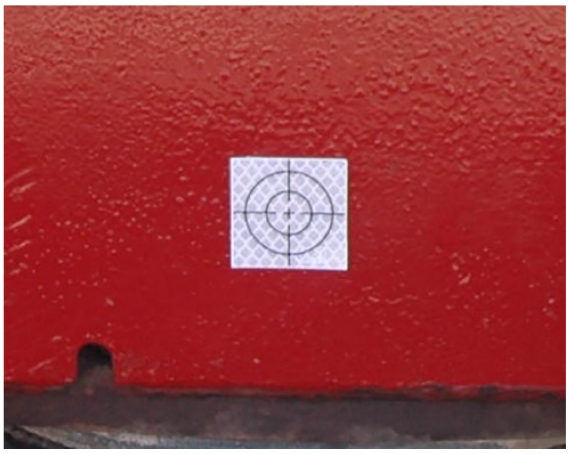

(b)

Fig. 2. The reflective markers fixed on one plate of the vehicle: (a) Overview; (b) Detail.

The inaccessibility to some areas of the yard had as main consequence that only one setup point per day was allowed. Figure $3 \mathrm{a}$ and Fig. $3 \mathrm{~b}$ show the schemas followed in the two days, where red points are the reference framework which will be illustrated ahead, blue points are the setup locations and points in magenta symbolize the markers on the plate; yellow lines represent topographic measurements. Setup location was moved, from $\mathrm{S} 1$ to $\mathrm{S} 2$, according to megashaker position and orientation (fundamental for markers visibility); for first day, shaking tests were performed in the first three areas, whereas, the day after, the experiments were conducted in Area4. Since there was only one setup point and it necessarily was very close to the operation area, this schema had two main consequences: first, most of the surveying was iso-determined, as markers on the plate have not been surveyed in a redundant way; secondly, stability of the setup point over the time could not be assumed, as the terrain at the setup location, could have experienced a minor sink effect, due to shacking actions. 


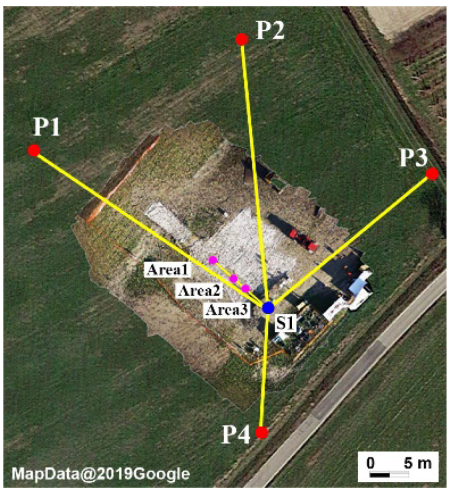

(a)

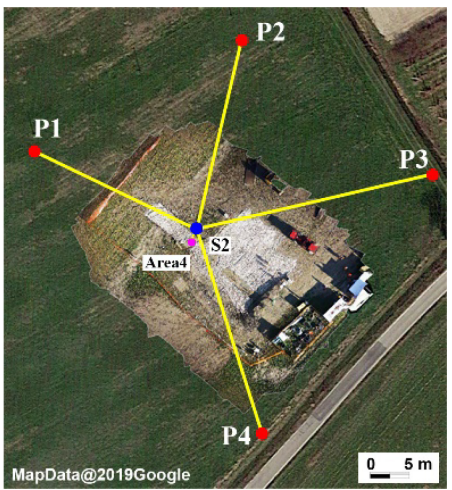

(b)

Fig. 3. Design of topographic measurements; the image shown is a merge: the large background image is from Google, while the central and detailed part is from our detailed orthophoto: (a) Day 1 , October $22^{\text {nd }}, 2018$; (b) Day 2, October $23^{\text {rd }}, 2018$. (Color figure online)

To overcome this problem, four benchmarks were created, which are visible in Fig. 3, having names P1-P4. According to the judgement of the geotechnical engineers involved, they were created far enough from the shaking area in order not to perceive vibrations and therefore to be stable. They represented the reference frame of the measurements and were observed before each measurement cycle following the Bessel's rule (target points were observed twice, in the so-called direct and reverse position).

\subsection{Terrestrial Laser Scanning Survey}

Trimble SX10 is also a laser scanner, having a range accuracy of about $1.5 \mathrm{~mm}$ at a $50 \mathrm{~m}$ distance and is capable to acquire the remarkable amount of $2.7 \cdot 10^{4}$ points per second [32]. Several scans were performed in an integrated way with the topographic survey. When a cycle of topographic measurements was started, its orientation could also be used to perform one or more scans; this gave us the advantage of a perfect co-registration between the different measurements acquired.

At the Pieve di Cento site three types of scans were performed, which are listed in Table 1. Panoramic scans are $360^{\circ}$ horizon tours acquired at a moderate resolution. They are useful to capture the whole context of the survey: point linear spacing is $40 \mathrm{~cm}$ at $200 \mathrm{~m}$ and completion time is around $12 \mathrm{~min}$. High resolution scans are focused on the strict operation zone, where are the four test areas. Point spacing is $4.5 \mathrm{~cm}$ at a $50 \mathrm{~m}$ distance, being the maximum range achieved while it is much smaller in the parts closer to the instrument, down to $2 \mathrm{~mm}$ at $3 \mathrm{~m}$. Presented figures clearly demonstrates that point clouds produced by laser scanning do not have a uniform density; acquiring the whole dig at high resolution took around $30 \mathrm{~min}$, which was incompatible with the experiment's schedule. High resolution partial scans were also acquired, embracing only one of the test areas: point density is the same, while acquisition time was around $8 \mathrm{~min}$.

Periodically acquired laser scans can be used to form the differences between them and thus to detect variations; this was done and is illustrated in the Sect. 4. 
Table 1. Characteristics of performed scans.

\begin{tabular}{l|l|l|l}
\hline Acronym & Explanation & Linear spacing of the point cloud & $\begin{array}{l}\text { Time } \\
\text { required }\end{array}$ \\
\hline PANORAMIC & $\begin{array}{l}360^{\circ} \text { scan } \\
\text { of the whole area }\end{array}$ & $\begin{array}{l}1 \mathrm{~cm} \text { at } 3 \mathrm{~m} ; \\
40 \mathrm{~cm} \text { at } 200 \mathrm{~m}\end{array}$ & $12 \mathrm{~min}$ \\
\hline HRES_WHOLE & $\begin{array}{l}\text { High resolution scan } \\
\text { of the whole dig area }\end{array}$ & $\begin{array}{l}2 \mathrm{~mm} \text { at } 3 \mathrm{~m} ; \\
4.5 \mathrm{~cm} \text { at } 50 \mathrm{~m}\end{array}$ & $30 \mathrm{~min}$ \\
\hline HRES_DETAIL & $\begin{array}{l}\text { High resolution scan } \\
\text { of one test area, out of four }\end{array}$ & Same as above & $8 \mathrm{~min}$ \\
\hline
\end{tabular}

\section{Results for Terrain Subsidence}

Section will report only a selection of the obtained results even if topographic and laser surveys were conducted on all areas and for all the 12 performed shaking tests. Indeed, the focus of present paper is on methodology, rather than on systematic illustration of subsidence induced by the experiments. To carry out analysis and prepare the shown figures, specifically written Matlab scripts and functions were coded.

\subsection{Area 3}

Area3 is characterized by horizontal drains and was involved in the shaking tests \#6 and $\# 7$, in late afternoon of October $22^{\text {nd }}$. Six targets, whose names range from ' $a$ ' to ' $\mathrm{f}$ ', were placed on the megashaker plate and theirs positions were measured three times, when plates were placed on the ground and just after the two shaking tests (Fig. 2a). Table 2 shows the time series of the events concerned.

Table 2. Description of Area3 measurements temporal sequence.

\begin{tabular}{l|l|l|l}
\hline \# Area & Date & Time & Description \\
\hline \multirow{3}{*}{3} & \multirow{2}{*}{$22^{\text {nd }}$ October } & $16: 52$ & Targets' measurement after plates were placed on the ground \\
\cline { 3 - 4 } & & $16: 57$ & $\# 6$ shaking test \\
\cline { 3 - 4 } & & $17: 05$ & Targets' measurement after the shaking \\
\cline { 3 - 4 } & & $17: 11$ & $\# 7$ shaking test \\
\cline { 3 - 4 } & & $17: 19$ & Targets' measurement after the shaking \\
\hline
\end{tabular}

For each measurement cycle, we determined the coordinates of markers a-f with respect to the same reference system. We then point-wise subtracted the coordinates determined at the 16:52 cycle from all the set of coordinates. Differences in x and y are negligible and are not reported here, where only the $\mathrm{z}$ component is illustrated, showing significant variations. Table 3 reports such differences: they are null for the 16:52 row by 
construction; for the other measurement cycles (17:05 and 17:19) differences highlight displacements. For the sake of clarity, point a, had a first downward shift of $11.4 \mathrm{~cm}$, after test \#6, and a further one of $7.7 \mathrm{~cm}$, after test \#7; the total displacement is then $19.1 \mathrm{~cm}$.

Table 3. Vertical displacements in Area3 due to shaking tests \#6 and \#7.

\begin{tabular}{|c|c|c|c|c|c|c|}
\hline \multirow[t]{2}{*}{ Time } & \multicolumn{6}{|l|}{$\Delta \mathrm{Z}[\mathrm{m}]$} \\
\hline & $\mathrm{a}$ & $\mathrm{b}$ & $\mathrm{c}$ & d & $\mathrm{e}$ & $\mathrm{f}$ \\
\hline $16: 52$ & 0.000 & 0.000 & 0.000 & 0.000 & 0.000 & 0.000 \\
\hline $16: 57$ & \multicolumn{6}{|c|}{ \#6 shaking test } \\
\hline $17: 05$ & -0.114 & -0.122 & -0.133 & -0.141 & -0.139 & -0.139 \\
\hline $17: 11$ & \multicolumn{6}{|c|}{ \#7 shaking test } \\
\hline $17: 19$ & -0.191 & -0.212 & -0.239 & -0.259 & -0.222 & -0.224 \\
\hline
\end{tabular}

Results obtained for the targets positioned in the lower part of the plate (from 'a' to ' $d$ ') and in the upper one ('e' and 'f') must be discussed separately (Fig. 2a) since the lower part can be considered integral to the ground as the plate is lying on it by gravity; the upper part is instead separated by a hydraulic system. In principle, the displacements measured for such targets cannot be directly attributed to the terrain. Problem is that, in some cases, there had been a very large subsidence of the land and the lower part of the device was totally buried, thus preventing us from taking any measurement. Observing the first four targets, the vertical displacement ranges between 19 to $26 \mathrm{~cm}$ showing a significant tilt of the plate; the last two targets show instead substantially equal values of about $22 \mathrm{~cm}$.

Figure $4 \mathrm{a}$ and Fig. $4 \mathrm{~b}$ give a graphical representation of vertical displacements as a function of time for the lower and upper parts of the plate, respectively. Dots represent the shift values obtained at each measurement epoch while the black vertical lines report the time of the two shaking events (\#6 and \#7). As no hypothesis can be done about the shifts of the targets between two measurements, dots were connected with horizontal dashed lines; they are dashed to underline their arbitrariness. Figure also shows the rotation suffered by the lower part of the plate; in the left part of the graphical, only one dot is visible because all the four markers considered have the same height, in the representation considered and explained before. In the central part four dots are visible because they no longer have the same height, meaning that their height variations have been odd; and, of course, they are all lower than the left dot, meaning that the plate has lowered on average. The same phenomenon, with even a major spread of the dots and inclination of the plate, happens in the right part. As previously observed, markers placed in the upper part of the shaking device, named ' $\mathrm{e}$ ' and ' $\mathrm{f}$ ', behave in a different way and remain almost horizontal. 


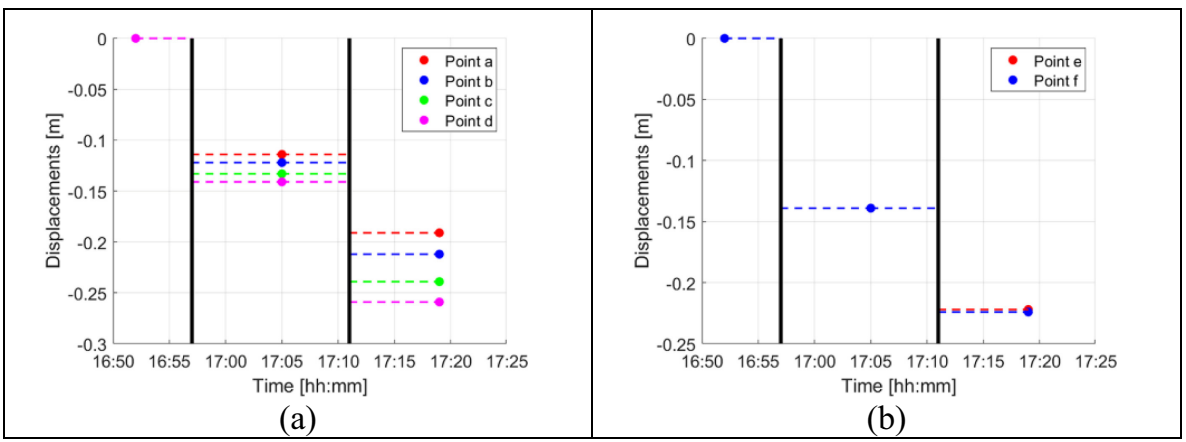

Fig. 4. Vertical displacements, for Area3, as a function of time; (a) Results for the four lower targets; (b) Results for the two upper ones. Black vertical lines represent the shaking events. (Color figure online)

The subsidence suffered by the terrain was also investigated by laser data: in principle, by comparing a point cloud acquired after a shake and another one surveyed before, the effects of the simulated earthquake should be delineated. Unfortunately, for the quite long time needed for acquisition, laser scans are not as dense in time as topographic surveys. Therefore, it is not guaranteed that there is a point cloud acquired just before one shaking event and another one surveyed just after. Nevertheless, for Area 3 it was possible to find a scan performed at the beginning of the day and another one acquired after shaking test \#7. Indeed, the latter was acquired in two steps, due to the presence of people near the megashaker, which obliged us to stop acquisition and to start a new one, after the area was cleared, to survey the missing part. Table 4 shows time series of the events involved.

Table 4. Time series of laser scans and shaking events for Area3.

\begin{tabular}{l|l|l|l}
\hline \# Area & Date & Time & Description \\
\hline \multirow{2}{*}{3} & $22^{\text {nd }}$ October & $09: 10$ & scan\#4 - HRES_WHOLE \\
\cline { 3 - 4 } & & $16: 57$ & $\# 6$ shaking test \\
\cline { 3 - 4 } & & $17: 11$ & $\# 7$ shaking test \\
\cline { 3 - 4 } & & $17: 21$ & scan\#8 and scan \#9 - Area3 HRES_DETAIL \\
\hline
\end{tabular}

To simplify the analysis, a significant profile was considered. A neighbourhood was generated for each point cloud; it is defined by the plane passing through the external and vertical face of the megashaker plate and has a depth of $15 \mathrm{~cm}$ forward and backward. All the points belonging to the neighbourhood were orthogonally projected onto the generating plane. 
Results are shown in Fig. 5 that shows the actual profiles: scan \#4, which was acquired before the shakes, in blue, and scans \#8 and \#9, which were acquired afterwards, in red. Figure reports the position of the markers (black dots), and the lower face of the plate (dashed black line), even not visible cause it sank around $20 \mathrm{~cm}$, to help the reader to interpret the picture. According to the figure, terrain was higher before (blue) the shake than after (red), on the left and right part of the graphical. This could point out that some subsidence took place after the shakes, thus lowering the red profile. But such lowering could also have been caused by the weight of the vehicle when its wheels passed there. Moreover, the graphical highlights that the red line (the after-shake profile) is higher than the blue one in the plate. This is due to terrain overflowing, rather than to the actual behaviour of the ground under shaking. The described example definitively clarifies that point clouds were not a good source for this study (Fig. 5).

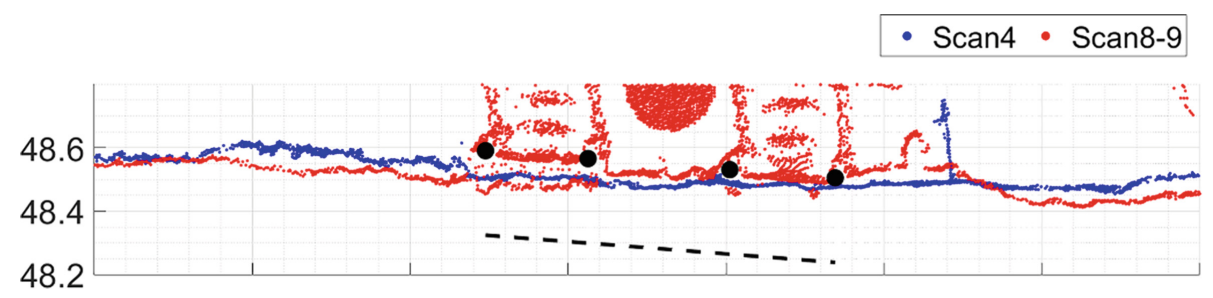

Fig. 5. Comparison between point clouds acquired by terrestrial laser scanning for Area4.

\subsection{Area4}

Area4 is characterized by the IPS mitigation technique and was involved in several tests. The present section only focuses on tests \#8 and \#9 performed in the late morning of $23^{\text {rd }}$ October. The second day, seven targets were applied to the vehicle: five in the lower part, named a-e, and two in the upper part, named f-g. Differently from Area3, some time has passed after the plates were laid on the terrain and before the shakes, to leave the terrain, dissipate internal strains (Table 5); this gave us the opportunity to perform two measurement cycles before the shakes. Data processing was carried out in the same way of Area 3; tables and graphical shown can be interpreted exactly in the same way.

Table 6 shows the displacements observed in Area4 due to the two shaking tests. Taking point ' $a$ ' as an example, the marker has subsided $0.7 \mathrm{~cm}$ during the dissipation phase, $13.3 \mathrm{~cm}$ after test \#8, and another $6.5 \mathrm{~cm}$, after test \#8; the total displacement is then $20.5 \mathrm{~cm}$. The first five targets, which are integral to the ground, have a vertical displacement ranging between 18 to $20 \mathrm{~cm}$; the other two targets show instead substantially equal values of about $14 \mathrm{~cm}$. Figure $6 \mathrm{a}$ and Fig. $6 \mathrm{~b}$ give the graphical representation of vertical displacements as a function of time for the lower and the upper parts of the plate, respectively. Dots represent the shift values obtained at each measurement epoch while the black vertical lines report the two shaking events (\#8 and \#9). The first two measurements relate to continuous line suggesting a linear-in-time displacement between them, 
while across the shaking events, the connections are represented by horizontal dashed lines. Figure once again shows the rotation suffered by the lower part of the plate while the upper part remains substantially horizontal.

Table 5. Description of Area4 measurements temporal sequence.

\begin{tabular}{l|l|l|l}
\hline \# Area & Date & Time & Description \\
\hline \multirow{2}{*}{4} & \multirow{2}{*}{$23^{\text {rd }}$ October } & $12: 19$ & Targets measurement after plates were placed on the ground \\
\cline { 3 - 4 } & & $12: 32$ & Targets measurements after the dissipation of terrain strains \\
\cline { 3 - 4 } & & $12: 40$ & $\# 8$ shaking test \\
\cline { 3 - 4 } & & $12: 47$ & Targets measurement after the shaking \\
\cline { 3 - 4 } & & $13: 08$ & $\# 9$ shaking test \\
\cline { 3 - 4 } & & $13: 16$ & Targets measurement after the shaking \\
\hline
\end{tabular}

Table 6. Vertical displacements in Area4 due to shaking tests \#8 and \#9.

\begin{tabular}{|c|c|c|c|c|c|c|c|}
\hline \multirow[t]{2}{*}{ Time } & \multicolumn{7}{|l|}{$\Delta \mathrm{Z}[\mathrm{m}]$} \\
\hline & a & $\mathrm{b}$ & $\mathrm{c}$ & d & $\mathrm{e}$ & $\mathrm{f}$ & g \\
\hline $12: 19$ & 0.000 & 0.000 & 0.000 & 0.000 & 0.000 & 0.000 & 0.000 \\
\hline $12: 32$ & -0.007 & -0.004 & -0.004 & -0.004 & -0.003 & -0.002 & -0.002 \\
\hline $12: 40$ & \multicolumn{7}{|c|}{ \#8 shaking test } \\
\hline $12: 47$ & -0.140 & -0.136 & -0.132 & -0.126 & -0.122 & -0.075 & -0.072 \\
\hline 13:08 & \multicolumn{7}{|c|}{ \#9 shaking test } \\
\hline $13: 16$ & -0.205 & -0.199 & -0.196 & -0.183 & -0.177 & -0.143 & -0.141 \\
\hline
\end{tabular}

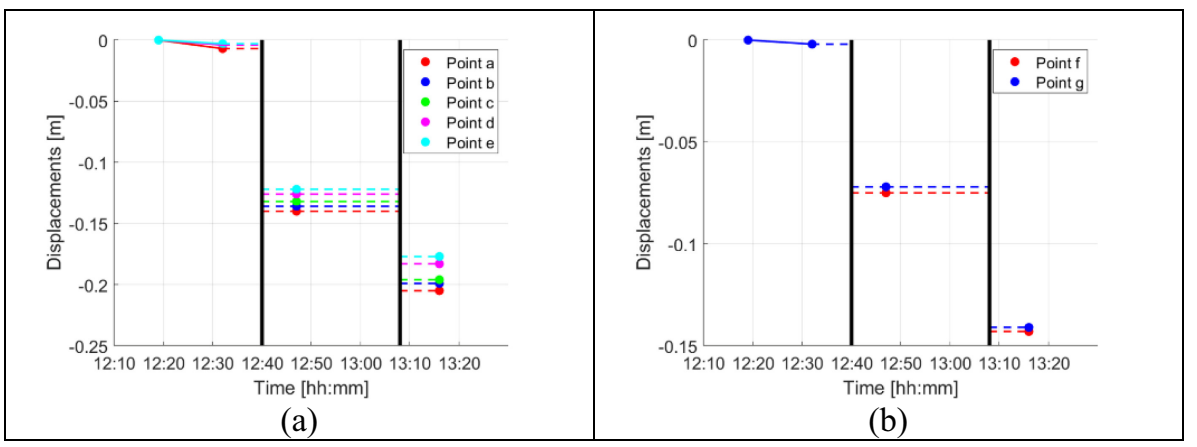

Fig. 6. Vertical displacements, for Area4, as a function of time; (a) Results for the five lower targets; (b) Results for the two upper ones. Black vertical lines represent the shaking events. 
Table 7. Time series of laser scans and shaking events for Area4.

\begin{tabular}{l|l|l|l}
\hline \# Area & Date & Time & Description \\
\hline \multirow{2}{*}{4} & \multirow{2}{*}{ 23 ${ }^{\text {rd }}$ October } & 08.32 & scan\#12 - HRES_WHOLE \\
\cline { 3 - 4 } & & $12: 40$ & \#8 shaking test \\
\cline { 3 - 4 } & & $13: 08$ & \#9 shaking test \\
\cline { 3 - 4 } & & $13: 13$ & scan\#18 - Area4 HRES_DETAIL \\
\hline
\end{tabular}

For Area4 it was possible, once again, to find two laser scans acquired before and after scans \#8 and \#9: they are listed in Table 7. They were processed in the same way described before and Fig. 7 was produced. Once again, the post-shake profile, shown in red, is at the same level of the blue profile or higher, as it seems to be in the area of the plate. As the plate significantly sinks, the surrounding terrain overflows: this might be interesting for geotechnics studies in general, but not to quantify the amount of the land subsidence (Fig. 7).

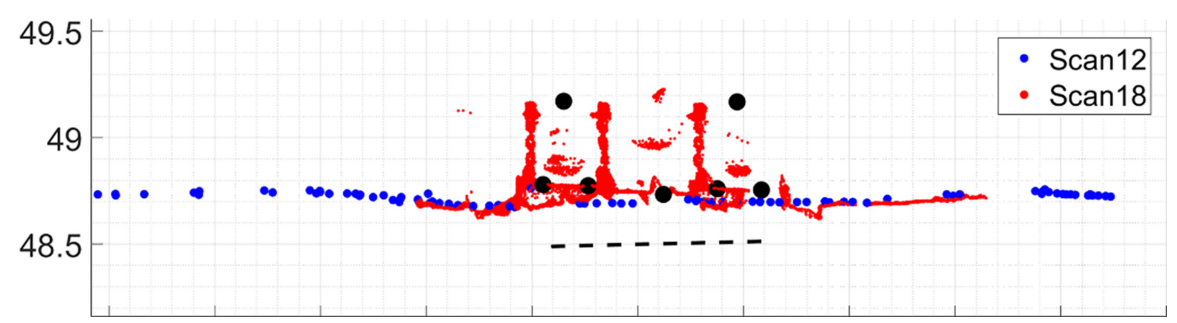

Fig. 7. Comparison between point clouds acquired by terrestrial laser scanning for Area4.

\section{Conclusion and Further Activities}

An experiment on soil liquefaction was performed in Pieve di Cento (Bologna, Italy) in October 2018. The Laboratory of Geomatics of the University of Pavia was requested to monitor the intensity of the induced subsidence. Two surveying techniques were applied: topographical surveying and terrestrial laser scanning. The use of Trimble SX10 integrated instrument was a point in favour. Due to several constraints of the LiquefACT field trial, the integration of laser scanner and total station allowed to choose the better solution for surveying switching between target measurements to point cluod generation; besides, total station functionalities consented to orient each data in the same reference frame through the observation of the four benchmarks.

Design of the surveys was complex and had to cope with several constraints coming from other aspects of the experiment. Nevertheless, it was possible to design a surveying schema which is sufficiently controlled and produced very precise measurements. We have been able to quantify sinking of the megashaker plate at each epoch of the experiment and before and after each shake. 
Geomatics proved to be very flexible and capable to adapt to varied scenarios and, at the same time, rigorous and highly precise. Trimble SX10 follows a modern concept of integrated topographical instrument and proved to be precise and adaptable; it seems particularly suited for monitoring applications.

The described project highlights that, to produce the expected results in demanding situations, the tools available to Geomatics must be used in appropriate and sometimes unconventional ways: to properly do so, a deep knowledge of the discipline and of its background is required. This seems in contrast with the ease of use of current instruments: it is easy to setup them and to take measurements on the field.

What is missing? Explicit evaluation of the accuracy of coordinates of plate's markers. This is due to a fundamental lack: we could not survey detail points from two setup positions, due to the constrains of the site. It will not be possible to fully overcome this limitation, but something can probably be done. We will introduce in the adjustment distance constraints, as it is reasonable to suppose that the distance between markers remained unchanged all along the day. This should allow us to come out with not only coordinates of markers, but also their precision.

Acknowledgements. Trimble-Italy is acknowledged here for lending us the SX10 instrument. This research has been carried out within the framework of the European LIQUEFACT project. The LIQUEFACT project has received funding from the European Union's Horizon 2020 Research and Innovation Programme under Grant Agreement No. 700748. This support is gratefully acknowledged by the authors.

\section{References}

1. Gomarasca, M.A.: Geomatics. In: Gomarasca, M.A. (ed.) Basics of Geomatics. pp. 1-17. Springer, Netherlands (2009). https://link.springer.com/article/10.1007/s12518-010-0029-6

2. Chiabrando, F., Donadio, E., Rinaudo, F.: SfM for orthophoto generation: Awinning approach for cultural heritage knowledge. Int. Arch. Photogramm. Remote Sens. Spatial Inf. Sci. XL5/W7, 91-98 (2015). http://dx.doi.org/10.5194/isprsarchives-XL-5-W7-91-2015

3. Xiao, W., Mills, J., Guidi, G., Rodríguez-Gonzálvez, P., Gonizzi Barsanti, S., GonzálezAguilera, D.: Geoinformatics for the conservation and promotion of cultural heritage in support of the UN sustainable development goals. ISPRS J. Photogramm. Remote Sens. 142, 389-406 (2018). https://doi.org/10.1016/j.isprsjprs.2018.01.001

4. Holmberg, S.C.: Geoinformatics for urban and regional planning. Environ. Plan. B Plan. Des. 21, 5-19 (1994). https://doi.org/10.1068/b210005

5. Bhatta, B.: Modelling of urban growth boundary using geoinformatics. Int. J. Digit. Earth. 2, 359-381 (2009). https://doi.org/10.1080/17538940902971383

6. De Lotto, R., et al.: Estimating the biotope area factor (BAF) by means of existing digital maps and GIS technology. In: Gervasi, O., et al. (eds.) Computational Science and Its Applications -- ICCSA 2015. ICCSA 2015. Lecture Notes in Computer Science, vol. 9157, pp. 617-632. Springer, Cham (2015). https://doi.org/10.1007/978-3-319-21470-2_45

7. Casella, V., Franzini, M., Padova, B., Lingesso, L., Pappani, G., Gentili, G.: Leica ADS40 imagery for disaster management. Ital. J. Remote Sens. Riv. Ital. di Telerilevamento. 43, 129-135 (2011). https://doi.org/10.5721/ItJRS201143210 
8. Giordan, D., Manconi, A., Remondino, F., Nex, F.: Use of unmanned aerial vehicles in monitoring application and management of natural hazards. Geomatics Nat. Hazards Risk 8(1), 1-4 (2017). https://www.tandfonline.com/action/journalInformation?journalCode=tgnh20

9. Gonzalez-Aguilera, D., Gomez-Lahoz, J.: Forensic terrestrial photogrammetry from a single image. J. Forensic Sci. 54, 1376-1387 (2009). https://doi.org/10.1111/j.1556-4029.2009.011 70.x

10. Pringle, J.K., et al.: The use of geoscience methods for terrestrial forensic searches. Earth-Sci. Rev. 114(1-2), 108-123 (2012)

11. Cosser, E., Roberts, G.W., Meng, X., Dodson, A.H.: Measuring the dynamic deformation of bridges using a total station. In: Proceedings of 11th FIG symposium on deformation monitoring (2003)

12. Radovanovic, R.S., Teskey, W.F.: Dynamic monitoring of deforming structures : GPS versus robotic tacheometry systems. In: Proceeding the10th FIG International Symposium on Deformation Measurements, pp. 61-70 (2001)

13. Palazzo, D.R., et al.: Dynamic monitoring of structures using a robotic total station. In: Proceedings of the Shaping the Change XXIII FIG Congress (2006)

14. Woźniak, M.: Investigation of using total station with ATR system in monitoring of displacements. Reports Geod. z. 1(76), 221-226 (2006)

15. Afeni, T.B., Cawood, F.T.: Slope monitoring using total station: what are the challenges and how should these be mitigated? South Afr. J. Geomatics. 2, 41-53 (2013)

16. Lienhart, W., Ehrhart, M., Grick, M.: High frequent total station measurements for the monitoring of bridge vibrations. J. Appl. Geod. 11, 1-8 (2017). https://doi.org/10.1515/jag-20160028

17. Berberan, A., Machado, M., Batista, S.: Automatic multi total station monitoring of a tunnel. Surv. Rev. 39, 203-211 (2007). https://doi.org/10.1179/003962607X165177

18. Lutes, J.A.: Automated Dam Displacement Monitoring Using a Robotic Total Station. Engineering (2002)

19. Jaafar, H.A.: Detection and localisation of structural deformations using terrestrial laser scanning and generalised procrustes analysis (2017)

20. Alba, M., Fregonese, L., Prandi, F., Scaioni, M., Valgoi, P.: Structural monitoring of a large dam by terrestrial laser scanning. Int. Arch. Photogramm. Remote Sens. Spat. Inf. Sci. 36, 6 (2006)

21. Prokop, A., Panholzer, H.: Assessing the capability of terrestrial laser scanning for monitoring slow moving landslides. Nat. Hazards Earth Syst. Sci. 9, 1921-1928 (2009). https://doi.org/ 10.5194/nhess-9-1921-2009

22. Giussani, A., Scaioni, M.: Application of TLS to support landslides study: survey planning, operational issues and data processing. Int. Arch. Photogramm. Remote Sens. Spat. Inf. 36, 318-323 (2004)

23. Travelletti, J., Oppikofer, T., Delacourt, C., Malet, J.-P., Jaboyedoff, M.: Monitoring landslide displacements during a controlled rain experiment using a long-range terrestrial laser scanning (TLS). In: International Archives of the Photogrammetry, Remote Sensing and Spatial Information Sciences - ISPRS Archives (2008)

24. Fischer, M., Huss, M., Kummert, M., Hoelzle, M.: Application and validation of long-range terrestrial laser scanning to monitor the mass balance of very small glaciers in the Swiss Alps. Cryosphere. 10, 1279-1295 (2016). https://doi.org/10.5194/tc-10-1279-2016

25. Erdélyi, J., Kopáčik, A., Lipták, I., Kyrinovič, P.: Pedestrian bridge monitoring using terrestrial laser scanning. In: Advances and Trends in Engineering Sciences and Technologies - Proceedings of the International Conference on Engineering Sciences and Technologies, ESaT 2015, pp. 51-56 (2016) 
26. Lõhmus, H., Ellmann, A., Märdla, S., Idnurm, S.: Terrestrial laser scanning for the monitoring of bridge load tests-two case studies. Surv. Rev. 50, 270-284 (2018). https://doi.org/10.1080/ 00396265.2016.1266117

27. Gawronek, P., Makuch, M.: TLS measurement during static load testing of a railway bridge. ISPRS Int. J. Geo-Inf. 8, 44 (2019). https://doi.org/10.3390/ijgi8010044

28. González-Aguilera, D., Gómez-Lahoz, J., Sánchez, J.: A new approach for structural monitoring of large dams with a three-dimensional laser scanner. Sensors 8, 5866-5883 (2008). https://doi.org/10.3390/s8095866

29. Kalkan, Y.: Geodetic deformation monitoring of Ataturk dam in Turkey. Arab. J. Geosci. 7(1), 397-405 (2012). https://doi.org/10.1007/s12517-012-0765-5

30. Medjkane, M., et al.: High-resolution monitoring of complex coastal morphology changes: cross-efficiency of SfM and TLS-based survey (Vaches-Noires cliffs, Normandy, France). Landslides 15(6), 1097-1108 (2018). https://doi.org/10.1007/s10346-017-0942-4

31. Mill, T.: Simulation of terrestrial laser scanning errors occurring during deformation monitoring. In: 3rd Joint International Symposium on Deformation Monitoring (JISDM) (2016)

32. Trimbe SX10 Datasheet. https://geospatial.trimble.com/sites/geospatial.trimble.com/files/ 2019-10/Datasheet-SX10ScanningTotalStation-EnglishUSL-Screen.pdf

33. Lachat, E., Landes, T., Grussenmeyer, P.: Investigation of a combined surveying and scanning device: the trimble SX10 scanning total station. Sensors (Switzerland). 17, 730 (2017). https:// doi.org/10.3390/s17040730

Open Access This chapter is licensed under the terms of the Creative Commons Attribution 4.0 International License (http://creativecommons.org/licenses/by/4.0/), which permits use, sharing, adaptation, distribution and reproduction in any medium or format, as long as you give appropriate credit to the original author(s) and the source, provide a link to the Creative Commons license and indicate if changes were made.

The images or other third party material in this chapter are included in the chapter's Creative Commons license, unless indicated otherwise in a credit line to the material. If material is not included in the chapter's Creative Commons license and your intended use is not permitted by statutory regulation or exceeds the permitted use, you will need to obtain permission directly from the copyright holder.

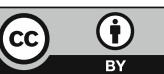

